\title{
Investigation of exposure of ships' painters to organic solvents
}

\author{
PAWEL I. MIKULSKI, RENATA WIGLUSZ, ANNA BUBLEWSKA, \\ and JANUSZ USELIS \\ Department of Hygiene and Clinic of Occupational Diseases, Institute of \\ Marine Medicine, Gdansk, Poland
}

\begin{abstract}
Mikulski, P. I., Wiglusz, Renata, Bublewska, Anna, and Uselis, J. (1972). Brit. J. industr. Med., 29, 450-453. Investigation of exposure of ships' painters to organic solvents. An analysis was carried out of the hazard to ships' painters working at different concentrations of toluene and xylene vapours in air. The authors point out that it is possible to use a joint determination of hippuric and methylhippuric acids for the assessment of mixed exposure. The problem of benzene contamination of solvents is considered. During the investigations exposure to toluene and xylene was found to impair the excretion of uric acid.
\end{abstract}

Industrial exposure is often associated with the hazards of exposure to a mixture of toxic substances. Spaces within ships are painted with chlorinated rubber and epoxy paints usually having as solvents a mixture of xylene and toluene.

The investigation of the relationship between the concentrations in air of solvent vapours and the quantities of metabolites excreted in the urine is usually carried out on volunteers in experimental chambers and on workers in selected workshops where the concentrations in air are kept constant. The working conditions of painters on ships depend on a number of complicated factors. The results obtained during the study of industrial exposure show marked divergences from the results obtained under experimental conditions (Pagnotto and Lieberman, 1967; Ikeda and Ohtsuji, 1969a, 1969b; Ogata, Tomokuni, and Takatsuka, 1970; Ogata, Takatsuka, and Tomokuni, 1971). In a preliminary assessment of the hazard from solvents when xylene is the general toxic agent, a separate determination of the metabolite of toluene can be omitted for practical reasons. This presumption was taken into consideration when working out a method for the joint determination of hippuric acids. The determination of other urine components was performed for supplementary assessment of the hazard.

\section{Material and methods}

Determination of solvent concentrations in air Gas chromatography 'Chrom II' with a flame ionization detector was used for this purpose. At least six air samples were taken at 1-hour intervals during one working shift into $5 \mathrm{ml}$ gas-tight Record syringes at various sites in each workplace (Lang and Freedman, 1969).

\section{Urine sampling}

Fifty-one urine samples were taken from painters working in small spaces of superstructures on board ship and in large shipholds, between the fourth and eighth working hour at shift change, during which time the solvent concentration in air was determined.

As there appeared to be two concentration groups in both the large and the small spaces, the workers examined were divided into two groups within each room type: group 1 -up to 100 p.p.m.; group II-above 200 p.p.m. of xylene in air. The results of urine samples were therefore grouped according both to the solvent concentrations in air noted during exposure of the workers and to the size of the spaces being painted.

Because the average specific gravity of urine of all the groups investigated approached 1.024 , the levels of hippuric acid were adjusted to a calculated specific gravity of 1.024 (Pagnotto and Lieberman, 1967; Ogata et al., 1970). The control group consisted of 21 healihy men. Urine from them was taken in the morning. 
Determination of hippuric acid Hippuric acid was determined by the method previously described (Mikulski and Wiglusz, 1970). One to $5 \mathrm{ml}$ of urine was adjusted with $\mathrm{HCl}$ to $\mathrm{pH} 2$ and diluted with distilled water to $100 \mathrm{ml}$. One millilitre of the diluted urine was extracted with $5 \mathrm{ml}$ of ethyl acetate, and $1 \mathrm{ml}$ of the extract was evaporated at a temperature of 90 to $110^{\circ} \mathrm{C}$. Subsequently $0.5 \mathrm{ml}$ of both $1.5 \%$-dimethylaminobenzaldehyde and $0.16 \% \mathrm{FeCl}_{3}$ in acetic acid anhydride were added. The samples were heated in a boiling water-bath for 10 minutes. After cooling, $4 \mathrm{ml}$ of ethanol were added and 10 minutes were allowed to elapse before colorimetric analysis at $470 \mathrm{~nm}$ was carried out.

Other determinations Phenol was determined in steam distillates with 4-aminoantipyrine (Bardodej, 1968), glucuronic acid by Marogg's method (1960), uric acid by Wells' method (1968), and creatinine by the picrate method of Kingsley and Schaffert (1953).

\section{Results}

The method of hippuric acid determination described allows a simultaneous determination of methylhippuric acid. Figure 1 shows the regression line for summed toluene and xylene concentrations in air in relation to the amount of hippuric acids excreted by the workers of all groups $(r=0 \cdot 81)$. As the toluene concentration represents about 10 to $20 \%$ of the total toluene and xylene concentrations, the relationship between the excretion of hippuric acids and the concentration of xylene alone was examined (Fig. 2). In this case the correlation coefficient is lower $(r=0.75)$. This indicates the usefulness of taking into consideration the ratio of summed solvent concentrations in air to the total of hippuric acids when making a preliminary assessment of the hazard. It is probable that a higher correlation may be obtained by the separate deter-

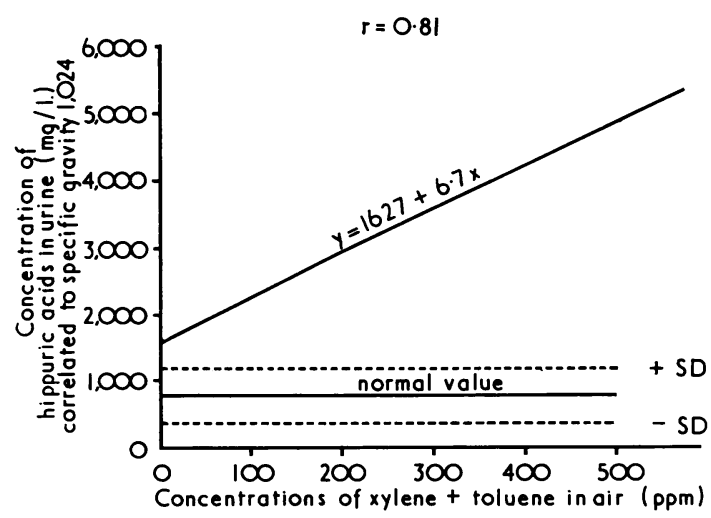

FIG. 1. Relationship between 'total' toluene and xylene concentrations in air and excretion of urinary hippuric acids.

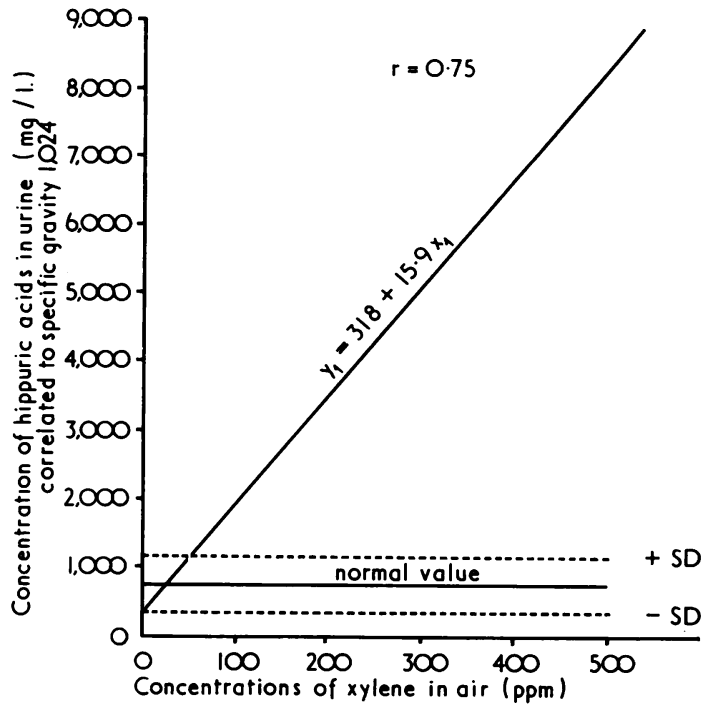

FIG. 2. Relationship between xylene concentrations in air and excretion of urinary hippuric acids.

mination of methylhippuric acid. This, however, requires chromatography.

As it is likely that the painting of comparable spaces in small rooms results in greater exposure than in large rooms, the painters were divided into those working in superstructures and those in large shipholds. The results presented in the Table show that, in all groups of workers exposed to xylene, there is a considerable increase in the amount of compounds determined as hippuric acids. There were no essential differences in hippuric acid excretion to indicate a relationship between the size of the room and the degree of hazard. However, in relation to solvent concentrations in air, it was observed that hippuric acid excretion was similar in the group I painters (those exposed to up to 100 p.p.m.) whether working in small or large rooms (Table).

The question of contamination of solvents with benzene is often ignored. The results presented in the Table indicate that even in those situations where benzene was not detectable in air a raised phenol level in the urine was found in exposed workers. The cause is probably an error in the determination of small amounts of benzene in air, the content of which may be different in individual batches of solvents and be undetectable at periodical air sampling.

In a study of exposure to solvents, investigation of the behaviour of other urine components seems to be important. The results of glucuronic acid excretion presented in the Table show that the contribution by coupling with this substance is sizeable. 
T A B L E

Levels of Hippuric Acid, Phenol, Glucuronic Acid, and Uric Acid in Urine OF WORKERS EXPOSED TO SOLVENT VAPOURS

\begin{tabular}{|c|c|c|c|c|c|}
\hline & \multirow{2}{*}{ Control } & \multicolumn{2}{|c|}{$\begin{array}{c}\text { Painters in small shipboard } \\
\text { superstructures }\end{array}$} & \multicolumn{2}{|c|}{ Painters in large shipholds } \\
\hline & & Group I & Group II & Group I & Group II \\
\hline $\begin{array}{l}\text { Solvent concentrations } \\
\text { in air (p.p.m.) } \\
\text { Benzene } \\
\text { Toluene } \\
\text { Xylene }\end{array}$ & & $\begin{array}{c}\text { Not detectable } \\
7 \\
93(23-133)\end{array}$ & $\begin{array}{c}6(4-8) \\
16(7-22) \\
256(212-365)\end{array}$ & $\begin{array}{c}\text { Not detectable } \\
11 \\
59(30-108)\end{array}$ & $\begin{array}{c}9(8-11) \\
53(18-88) \\
398(230-538)\end{array}$ \\
\hline $\begin{array}{l}\text { No. of samples examined } \\
\text { Mean specific gravity }\end{array}$ & $\begin{array}{c}21 \\
1 \cdot 024 \\
(1 \cdot 014-1 \cdot 030)\end{array}$ & $\begin{array}{c}21 \\
1.022 \\
(1 \cdot 010-1 \cdot 030)\end{array}$ & $\begin{array}{c}9 \\
1 \cdot 024 \\
(1 \cdot 021-1 \cdot 027)\end{array}$ & $\begin{array}{c}8 \\
1 \cdot 026 \\
(1 \cdot 015-1 \cdot 030)\end{array}$ & $\begin{array}{c}13 \\
1.028 \\
(1 \cdot 016-1 \cdot 034)\end{array}$ \\
\hline Creatinine (g/l) & $\begin{array}{c}1.63 \pm 0.66 \\
(0 \cdot 4-3 \cdot 0)\end{array}$ & $\begin{array}{l}1 \cdot 57 \pm 0 \cdot 65 \\
(0 \cdot 85-3 \cdot 2)\end{array}$ & $\begin{array}{l}2 \cdot 1 \pm 0 \cdot 55 \\
(1 \cdot 5-2 \cdot 5)\end{array}$ & $\begin{array}{l}1 \cdot 9 \pm 1 \cdot 1 \\
(1 \cdot 2-3 \cdot 1)\end{array}$ & $\begin{array}{c}2 \cdot 1 \pm 0 \cdot 13 \\
(2 \cdot 0-2 \cdot 5)\end{array}$ \\
\hline $\begin{array}{l}\text { Hippuric acid }(\mathrm{mg} / \mathrm{l}) \\
\text { corrected for specific } \\
\text { gravity } 1 \cdot 024\end{array}$ & $\begin{array}{l}790 \pm 430 \\
(310-1640)\end{array}$ & $\begin{array}{c}1812 \pm 1275 \\
(403-3834)\end{array}$ & $\begin{array}{l}3821 \pm 1113 \\
(2200-5795)\end{array}$ & $\begin{array}{c}1998 \pm 1197 \\
(994-4567)\end{array}$ & $\begin{array}{l}5500 \pm 1690 \\
(4779-8244)\end{array}$ \\
\hline $\begin{array}{l}\text { Phenol }(\mathrm{mg} / \mathrm{l}) \\
\text { Glucuronic acid }(\mathrm{mg} / \mathrm{l}) \\
\text { Uric acid }(\mathrm{mg} / \mathrm{l})\end{array}$ & $\begin{array}{l}7 \cdot 9 \pm 4 \cdot 3 \\
(3 \cdot 0-20 \cdot 9) \\
480 \pm 235 \\
(100-900) \\
939 \pm 318 \\
(480-1600)\end{array}$ & $\begin{array}{c}12 \cdot 4 \pm 7 \cdot 4 \\
(4 \cdot 0-28 \cdot 9) \\
1230 \pm 1060 \\
(300-3590) \\
806 \pm 326 \\
(200-1500)\end{array}$ & $\begin{array}{c}47 \cdot 0 \pm 6 \cdot 1 \\
(4 \cdot 0-90 \cdot 0) \\
4000 \pm 2780 \\
(1530-7080) \\
353 \pm 60 \\
(285-400)\end{array}$ & $\begin{array}{c}43 \cdot 4 \pm 35 \cdot 9 \\
(9 \cdot 1-178 \cdot 9) \\
2660 \pm 820 \\
(2020-2400) \\
537 \pm 193 \\
(320-855)\end{array}$ & $\begin{array}{c}66 \cdot 4 \pm 52 \cdot 2 \\
(29 \cdot 8-179 \cdot 0) \\
3500 \pm 420 \\
(2800-3880) \\
372 \pm 172 \\
(187-405)\end{array}$ \\
\hline
\end{tabular}

The values represent means $\pm \mathrm{SD}$; ranges in parentheses

although most of the excreted substance is coupled with glycine. Glucuronic acid concentrations in the urine of exposed workers may increase as much as five-fold compared with the normal level but there is no proportionality either to the excretion of hippuric acid or to the concentration of solvents in air.

Because of the contribution of the glycine pool to the excretion of toluene and xylene metabolites, the excretion of uric acid is affected. The observed reduction of uric acid excretion, which is inversely proportional to the amount of hippuric acid excreted, is in agreement with the experimental data obtained by using large doses of benzoic acid injected or administered orally (Quick, 1931).

\section{Discussion}

Most of the methods used for the determination of toluene metabolites determine the summed content of aromatic acids. Methylhippuric acids are determined together with hippuric acid (Ogata, Tomokuni, and Takatsuka, 1969; Mikulski and Wiglusz, 1970). This is acceptable for the estimation of mixed toluene and xylene exposure, the more so because, in most countries, approximate values of the maximal allowable concentrations for both solvents are accepted.

Though the use of the simple term 'total' seems to be questionable, practical reasons and the need for a quick assessment of exposure to these solvents justify a simplification. Certainly, a complete estimation of exposure has to take into account the differences in toxicity of xylene and toluene and the maximal allowable concentrations for these solvents. An assessment of exposure to the methyl derivates of benzene is easier and does not involve a significant error when, as in our investigation, one of the solvents represents only a low percentage of the total.

The increased glucuronic acid excretion is a result of exposure to organic solvents but, as is already known, the excretion of this compound shows no close correlation with exposure.

The metabolic pathways and excretion of toxic substances undoubtedly influence other physiological processes. One of these is the inhibition of uric acid excretion. Though the value of this inhibition for the monitoring of exposure is somewhat doubtful, it might be worth while to consider any possible effects on those chronic diseases in which the metabolism or excretion of uric acid is also affected. This problem will be the subject of further study 
together with other physiological changes which may take place due to exposure.

\section{References}

Bardodej, Z. (1968). Beurteilung der Benzol- und Phenolgefährdung mit dem Phenoltest. Arbeitsmed. Sozialmed. Arbeitshyg., 3. 141-142.

Ikeda, M., and Ohtsuji, H. (1969a). Hippuric acid phenol, and trichloroacetic acid levels in the urine of Japanese subjects with no known exposure to organic solvents. Brit. J. industr. Med., 26, 162-164.

_ - and $-(1969 \mathrm{~b})$. Significance of urinary hippuric acid determination as an index of toluene exposure. Brit. $J$. industr. Med., 26, 244-246.

Kingsley, G. R., and Schaffert, R. R. (1953). Creatinine. In Standard Methods of Clinical Chemistry, edited by $\mathrm{M}$. Reiner, vol. 1, pp. 55-59. Academic Press, New York

Lang, H. W., and Freedman, R. W. (1969). The use of disposable hypodermic syringes for collection of mine atmosphere samples. Amer. industr. Hyg. Ass. J., 30, 523-526.

Marogg, J. (1960). Die quantitative Glucuronsäuerebestimmung. Arzneimittel-Forsch., 10, 987-990.

Mikulski, P., and Wiglusz, Renata (1970). A simple micromethod of determination of hippuric acid in the urine. Bull. Inst. mar. Med., Gdańsk, 21, 129-138.
Ogata, M., Tomokuni, K., and Takatsuka, Y. (1969) Quantitative determination in urine of hippuric acid and $m$ - or $p$-methylhippuric acid, metabolites of toluene and $m$ - or $p$-xylene. Brit. J. industr. Med., 26, 330-334. and - (1970). Urinary excretion of hippuric acid and $m$ - or $p$-methylhippuric acid in the urine of persons exposed to vapours of toluene and $m$ - or $p$-xylene as a test of exposure. Brit. J. industr. Med., 27, 43-50.

-, Takatsuka, Y., and Tomokuni, K. (1971). Excretion of hippuric acid and $m$-or $p$-methylhippuric acid in the urine of persons exposed to vapours of toluene and $\mathrm{m}$ or $p$-xylene in an exposure chamber and in workshops, with specific reference to repeated exposures. Brit. $J$. industr. Med., 28, 382-385.

Pagnotto, L. D., and Lieberman, L. M. (1967). Urinary hippuric acid excretion as an index of toluene exposure. Amer. industr. Hyg. Ass. J., 28, 129-134.

Quick, A. J. (1931). The conjugation of benzoic acid in man. J. biol. Chem., 92, 65-85.

Wells, M. G. (1968). Improved method for the determination of uric acid in blood and urine. Clin. chim. Acta, 22, 379-384.

Received for publication September 6, 1971 